\title{
Household environmental sanitation practices in Katsina Metropolis
}

\author{
Komolafe A. Olajide \\ Department of Home Economics, Federal College of Education, \\ P.M.B. 2041, Katsina, Nigeria
}

\begin{abstract}
The Study focused on household environmental sanitation practices in Katsina Metropolis. Survey research design was adopted for the study. Structured questionnaire was used for data collection from 250 households which were randomly selected from five wards in the study area. Multistage sampling technique was used to select respondents for the study. Four research questions were answered. Data collected for the study were analyzed, using frequency counts and mean to answer the research questions. The findings of the study revealed that households in Katsina metropolis dispose their solid wastes in vacant or unused plots, back of homes, along the road and drains among others. Some strategies such as implementation of national environmental sanitation policy. Provision and use of waste disposal facilities, inculcation of right attitudes in householders/homemakers on waste disposal through the introduction of environmental education in primary and post primary schools curriculum, were identified to improve environmental sanitation practices. Based on the findings, some recommendations were made to improve on the practices.
\end{abstract}

Keywords: Katsina Metropolis; household; environmental education

\section{INTRODUCTION}

The environment is the entire matrix in which man and all things exist. Akhilome and Idamokoro (2001) defined environment as all the interacting factors and circumstances that surround, influence and direct the growth and behaviour of individual beings, groups, species and communities. It can also be referred to as all aspects of people and their surroundings whether it affects them individually or in groups. Nigerian environmental study team (NEST, 1995), defines environment as the combination of natural objects (living and non-living), objects, made by human beings, the interrelationships between these various circumstances which surround people on earth.

The environment, according to NEST (1995) is made of physical and socio-cultural components. The physical components include non-living (land, water, air), living things (plants, animals, human beings, micro-organisms) and man-made features which include human settlement and all associated infrastructures, such as roads, footpaths, farms, buildings, and so on. The socio- cultural components include: social, economic, cultural, educational, religious, relationships among others. The physical environment is where human beings live as household and provide the resources and ecological processes which make life possible (Ukwe, 2008) 
Households are group of people living together in a common residence or apartment as consuming units in a physical environment. The daily household activities and consumptions practices are bases of waste generation which is the primary focus of this study. Solid wastes are consequences of human activities which involves the production of goods and services and the consumption of natural resources (Ukwe, 2004). The wastes are solid and are discarded as useless and unwanted. Two major types of wastes are generated in Nigerian households. These are decayed organic wastes (food reminants, leaves and animals) and nondecayable inorganic wastes (tins, cans, synthetic wrappings plastic containers, glasses, cellophane bags etc) (Ahia, 2000).

Solid waste disposal problems are found virtually in all the big cities in Nigeria (Onwuendo, 2007). This is largely due to the increasing rate of population growth, urbanization, and increase in human, domestic, commercial and industrial activities (Onibokun and Kumuyi, 20006). The problem of waste management practices may be as a result of poverty, home makers environmental illiteracy and the lack of legislation and enforcement. This has resulted to ineffective management of solid waste in many urban towns in Nigeria (Akpan and Usoro, 2005). In Katsina Metropolis the generally adopted method of waste disposal is the indiscriminate dumping system. The indiscriminate method of waste disposal is a system whereby all solid wastes are not sorted before being disposed in open gullies, streets, rivers, streams, valleys and abandoned pits. This has led to more determination of the local environment (Ahmed, 2003). Majority of households engage in the use of inappropriate waste disposal bins, such as old cartons and broken plastic buckets for storage and are later disposed in irregularly evacuated dumpsites provided by the Katsina State Environmental Protection Agency (KTSEP A), or any available open space.

The problem of household solid wastes disposal, most especially in Nigerian cities has become one of the most intractable challenges facing the country today. Refuse and other solid wastes which form the bulk of household wastes in Nigeria, pose serious environmental problems, besides unsightly appearance and stink, they also promote vector breeding and transmission of diarrhea and other parasitic infection as noted by Sridhar and Adeyo in Ukwe (2004). Anozie (2008) noted that environmental problems originated from the process of development partly from poverty and environmental illiteracy.

The consequence of indiscriminate dumping of household solid wastes is various environmental and health problems. This includes inter-alia; blockage of drains, flood hazards, air, water and land pollution, provision of breeding places for pests, spread of diseases such as malaria from mosquitoes, cholera, dysentery, diarrhea and offensive odour. There is a link between the environment and human health which calls for functional environmental sanitation in Katsina metropolis. Environmental sanitation refers to the process of protecting health in the environment including the arrangement for the disposal of refuse, World Health Organization (WHO, 1995) defines environmental sanitation as the promotion of hygiene. It can also be the Prevention of diseases and other consequences of health, relating to environmental factors, Environmental sanitation is important and the right steps in creating and maintaining condition in the environment that can promote good and effective health.

Federal Republic of Nigeria (2005) defines environmental Sanitations as the principles and practice of effecting healthful and hygienic condition in the environment to promote public health and welfare, improve quality of life, reduce poverty and ensure a sustainable environment. The main objective of environmental sanitation is to create and maintain conditions in the environment that will promote good and efficient health and prevent 
diseases. The importance of environmental sanitation is to prevent infectious diseases such as air and water borne diseases, to create wealth by recycling non-biodegradable items for use.

Hygienic disposal of household solid wastes play a role in the provision of sound health and safe environment for the family. Effective management of solid wastes will reduce the incidence of food and water borne diseases such as cholera, dysentery, typhoid fever, diarrhea and food poisoning (United Nations, 2003). These however, have significant health and economic implications. The economic development of members of any household depends to a large extent on the health of the individuals, which to a large extent also depends on the hygienic conditions of their environment. It is on the basis of this, that this study investigated the environmental Sanitation Practices of households in Katsina metropolis as a way of preferring solution for improvement.

\section{PURPOSE OF STUDY}

The major purpose of the study was to investigate the Environmental Sanitation Practices of Households in Katsina metropolis. Specifically, the study determined:

1. Environmental Sanitation Practices of Households in Katsina metropolis.

2. Factors that influence household solid waste disposal method in Katsina metropolis

3. Consequences of improper household solid wastes disposal practices in Katsina metropolis.

4. Strategies for improving household environmental sanitation practices in Katsina metropolis

\section{METHODOLOGY / RESEARCH DESIGN}

\section{1. The study adopted a survey research design. This allowed information to be gathered from an unbiased representative group of interest (Owens, 2002). Information's were gathered from home makers in households of Katsina Metropolis.}

\section{Population of the Study}

The population of the study was all the households in Katsina metropolis. There are 4,987 registered housing units in Katsina metropolis (Katsina State ministry of Works, transport and housing, 2009).

\section{Sample and Sampling Technique}

Multistage sampling techniques was used in the selection of respondents for study. Five wards in the metropolis (Kwado/GRA/Daura road ward/ Sabon Layi/ Kofar Soro/ Central Urban ward/ Kofar Kwaya/ Sabon Ungwa/ Kofar Guga ward/ General hospital/ Kofar Sauri/ Kofar durbi Ward and Kofar Marusa/ WTC/ New Layout Ward) were purposively sampled for the study because of the serious environmental challenges posed by waste management in these areas. 50 households were randomly selected from each of the five wards to make a total of 250 households. One home maker in each household was selected to respond to the questionnaire. 


\section{Instrument for Data Collection}

A structured questionnaire was the instrument used for data collection. This was developed based on extensive review of literature and the objective of the study. A five (5) point Likert scale of strongly agree to strongly disagree was used to collect data. The instruments were validated by three Lecturers. Two of them in Home Economics Department Federal College of Education, Katsina and one environmental Specialist in the Department of environmental studies Ahmadu Bello University, Zaria. The reliability was determined by using Cronbach Alpha procedure as it deals with multiple score items. A reliability coefficient of 0.88 was obtained.

\section{Data Collection and Analysis}

Two hundred and forty five (250) copies of the instrument were administered with the help of one trained research assistant. The entire questionnaire distributed were filled and returned making a returned rate of 100 percent. The data from the questionnaire were analyzed, using mean to answer the three (3) research questions. Any item with a mean score of 3.50 and above was regarded as accepted while any mean below 3.50 was regarded as rejected.

\section{RESULTS}

Table 1. Mean responses on environmental sanitation practices of households.

\begin{tabular}{llll} 
S/N & Environmental Sanitation Practices of Households & $\overline{\mathbf{X}}$ & Remarks \\
\hline 1 & Solid wastes are sorted before disposal & 2.15 & Disagreed \\
2. & Solid wastes are stored according to types before Disposal & 2.33 & Disagreed \\
3. & Solid wastes are disposed in vacant plots & 4.05 & Agreed \\
4. & Road sides are used as dump sites & 3.58 & Agreed \\
5. & Open pits are used as dump sites & 3.52 & Agreed \\
6. & Gullies are used as dump sites & 3.62 & Agreed \\
7. & Incineration in front or back of homes & 3.54 & Agreed \\
8. & Drains are used as dump sites & 3.65 & Agreed \\
9. & Government approved dump site facilities are used & 2.74 & Disagreed \\
\hline
\end{tabular}

$\mathrm{N}=250$

Table 1 above shows that the respondents accepted six (6) out of nine (9) items identified as environmental Sanitation Practices of Households in Katsina Metropolis. The six (6) items met the cut off point of 3.50 and above while items 1, 2 and 9 rated 3.15, 2.33 and 
2.74 were not accepted. The six (6) item are therefore regarded as Environmental Sanitation Practices adopted by households in Katsina Metropolis.

Table 2. Mean responses of respondents on the factors influencing HSW disposal methods.

\begin{tabular}{lcc}
\hline S/N $\quad$ Factors influencing HSW disposal Methods & $\overline{\mathbf{X}}$ & Remarks \\
\hline 1. Lack of awareness of the importance of environmental sanitation & 4.35 & Agreed \\
2. Lack of environmental education & 4.28 & Agreed \\
3. Increase in population & 4.12 & Agreed \\
4. Indiscriminate wastes disposal & 3.78 & Agreed \\
5. Lack of access route to waste collection site & 4.15 & Agreed \\
6. Lack of Public cooperation & 3.75 & Agreed \\
7. Grossly inadequate public dump sites & 4.13 & Agreed \\
8. Poor knowledge of wastes disposal practices & 4.25 & Agreed \\
9. Lack of adequate monitoring and supervision of & & \\
$\quad$ environmental sanitation by government sanitation officials. & 4.47 & Agreed \\
10. Lack of environmental sanitation law enforcement & 4.17 & Agreed \\
11. Lack of waste recycling facilities & 4.49 & Agreed \\
\hline
\end{tabular}

$\mathrm{N}=250$

Table 2 above shows that the respondents accepted all the eleven (11) items as factors influencing the adoption of wastes disposal methods by households in Katsina Metropolis. They all met the cut off point of 3.50 and above.

Table 3. Mean responses of respondents on the consequences of improper HSW disposal practices.

\section{S/N Consequences of improper HSW disposal practices}

$\overline{\mathrm{X}} \quad$ Remarks

1. Flooding of the environment resulting from blockage of drainage system.

4.06 Agreed

2. Lowers the quality and esthetics of environment

4.20 Agreed

3. Increase in population/urbanization

4.12 Agreed

4. Constitute sources of stench and offensive odour

4.35 Agreed

5. Spread of communicable diseases

4.25 Agreed 
6. Contaminated foods

7. Flies and rodents infestation

8. Mosquitoes infestations
4.15 Agreed

4.24 Agreed

4.37 Agreed $\mathrm{N}=250$

Table 3 above reveals that the respondents accepted all the eight (8) items identified as consequences of improper HSW disposal practices by households in Katsina Metropolis. They all met the cut-off point of 3.50 and above.

Table 4. Mean responses of respondents on strategies for improper household environmental sanitation practices.

S/N Strategies for improving Environmental Sanitation practices $\overline{\mathbf{X}} \quad$ Remarks

1. Wastes should be sorted according to types before disposal

2. Provision of adequate waste disposal facilities by government

3. Dump wastes in government approved public waste disposal facilities

4. Avoid indiscriminate dumping of wastes

5. Empty waste disposal facilities regularly

6. Wash and disinfect waste bins regularly

7. Enforcement of environmental sanitation laws

8. Monitoring and supervision by environmental sanitation health officials

9. Inculcation of environmental education (EE) in the

school curriculum at all levels of Nigerian educational

programmes

10. Enlightenment campaign programmes by government at

all levels, NGOs, Home Economics extension services
4.39 Agreed

3.87 Agreed

4.24 Agreed

4.27 Agreed

3.98 Agreed

4.21 Agreed

3.8 Agreed

4.03 Agreed

4.32 Agreed

4.01 Agreed

$\mathrm{N}=250$

Table 4 above reveals that the mean response of the respondents on the strategies for monitoring environmental sanitation practices were all above 3.5. The result shows that the 
respondents accepted all the items as the strategies for improving environmental sanitation practices in Katsina metropolis.

\section{DISCUSSION}

The results of the data analysis in Table 1 reveals that respondents do not sort their water or stored them according to types before disposal and do not also use government approved dump site (Table 1 items 1,2, \& 9). This is not in agreement with Anyakoha and Eluwa (2010), who stressed the need for solid wastes to be sorted according to type before final disposal. Enueze (2004) opined that households do not normally sort their refuse before disposal. Items 3-8 show that respondents dispose their wastes in vacant plots, road sides, open pits, gullies, drains and by burning. This is in consonance with Anyakoha (1995) who stated that "households deposit their wastes in vacant or unused plots". The results of Table 1 reavealed that all the methods adopted by households in Katsina Metropolis are improper. The most appropriate disposal practices is the use of government approved dump site facility.

The findings were in agreement with the literature and supported by Federal Government of Nigeria (1998) which stressed the enhancement management strategies of solid wastes is through source reduction, recycling, incineration and land filling. Most of the households that are far from those dump site facilities where available, find it difficult to get there and use them. They thus resort to such disposal practices of dumping wastes along the road as shown in Table 1 Items 3-8.

The respondents agreed in all the eleven (11) items as factors influencing HSW disposal methods. Some of these factors include: the lack of awareness of the importance of environmental sanitation, lack of environmental education, increase in population among others. The findings were in agreement with the literature and supported by Folarin (2005) and Ezeoguine (2005) who attributed the factors influencing HSW disposal methods as increase in population, urbanization poor attitude towards waste disposal. Lack and inadequate disposal facilities. The views expressed by the respondents has helped to validate the findings of this study on factors influencing the adopted methods of HSW disposal practices.

The respondents agreed on all the eight (8) items as the consequences of improper HSW disposal practices. The indiscriminate dumping of refuse in unauthorized sites as shown in Table 1, items 3-8, lowers the quality and aesthetics of the environment as it makes the environment to look dirty and also causes environmental pollution as noted by Lapin (1997) and Ogbene, (2003). The respondents observed that the greatest problem encountered as a result of improper management of HSW generated within the study area was unsightly environment, surface and underground water pollution, flooding and diseases.

Akpan and Usoro in Awo, (2007), noted that indiscriminate heaps of wastes produce offensive smell in the environment and as well makes the surroundings unsightly. When rain water washes off such wastes, they can lead to water pollution. This is also supported by Ukwe (2004) who observed that HSW constitutes a serious environmental hazard, unsightly and stink, promote vector breeding and encourages transmission of diarrhea and other parasitic infections. Jimoh (2003) also agreed that the most paramount problems facing cities in Nigeria are environmental problems of air, water and land pollution, flooding, health hazards, pile of sediments (aesthetic destruction), unsanitary conditions and low level hygienic standards. In a research conducted by Moloku (2008) in randomly selected cities in the North, South, East and West of Nigeria, the findings revealed that plastic (solid) waste 
clogged gutters and drains causing flooding and stagnant pool of water, where mosquitoes breed and spread malaria as seen in items $4,7 \& 8$ in Table 3.

All the ten (10) items on strategies for improving environmental practices were agreed upon by the respondents in Table 4. items 2, 3, 5, 7-10, were agreed by respondents on the role of government in HSW management. In support of this, the findings of Ezeoguine (2002) observed that it is the duty and responsibility of the government to collect wastes from dumpsites and disposal to the final spot. The findings of Ezeoguine (2005) and Folarin (2005) in line with the study, emphasized the need for public Enlightenment campaign by the government, environmental sanitation officials, NGOs, Home Economics extension services. This is hoped to create awareness on the problems associated with improper waste disposal practices.

Items $1,4, \& 6$ in Table 4, also stressed the roles of individuals /home-makers as strategies for improving environmental sanitation practices. These include sorting and storing of wastes according to types before disposal, avoid indiscriminate dumping of wastes and washing and disinfecting waste bins regularly.

The findings were in line with literature and supported by Saka (1995) who noted that ideally, each household is supposed to have a refuse container with cover/lid to store wastes and regularly dispose at government authorized site.

\section{CONCLUSION AND RECOMMENDATIONS}

In conclusion, the study observed that the practices of disposing HSW adopted by households in Katsina Metropolis are ineffective for a sustainable environment.

Although, the state government has relentlessly invested heavily in both human and material resources in the area of environmental cleanliness and beauty of the metropolis.

However, a lot is still required to be done in such areas as: provision of more disposal facilities in strategic locations, regular evacuation of wastes from disposal facilities to dump sites and education / Enlightenment campaign on the need for proper waste disposal.

On the basis of the findings of the study, the following recommendations were made:

1. Sponsored public Enlightenment and education programmes through the media (news papers, magazines, radio, television etc), schools, religious institutions and community centres to promote the right culture of a sustainable environment.

2. Government should provide recycling plants that would be used for the recycling of wastes and at the same time lead to job and wealth creation.

3. Environmental education should be incorporated into the school curricula at all levels of the Nigeria education system

4. The state government should enforce the environmental sanitation laws with commensurate penalty for anyone who contravenes the law.

5. There should be proper funding of environmental protection agencies by the state government to enhance efficient waste management. 


\section{References}

[1] Ahia C. N., Nigerian Vocational Journal (2000) 23-24.

[2] Akhilome A. A. Idamokoro G. E., Benin Journal of Environmnetal Education 1(1) (2001) 79-87.

[3] Akpan A. E., Usoro C. I., Journal of Home Economics Research 6(2) (2005) 200-2005.

[4] Ahmed Y. A. (2003). Wasste Generation and Management Techniques, In Jona, H.I "'and Fabiyi, LP (eds) Contemporary Issues on Environmental Studies Ilorin: Haytee Press.

[5] Anozie G. O., Journal of Home Economics Research 9(20) (2008) 72-78.

[6] Anyakoha E. U., Nigerian Vocational Journal VIII (1995) 67-76.

[7] Anyakoha E. U., Eluwa M. (2010). Home Management: for Schools and Colleges. Onitsha: African FEP Publishers Ltd.

[8] Awo O. K. (2007). Strategies for Enhancing Solid Waste Disposal Practices of Households in Urban Areas of Katsina State. Unpublished M.Ed Thesis submitted to the Department of Vocational Teacher Education, University of Nigeria Nsukka.

[9] Enueze B. C. (2004). Comparative Analysis of the Composition of Household Waste in Ibadan North LGA. Unpublished M.Sc Thesis Department of, Geography, University of Ibadan.

[10] Ezeoguine J. A. (2002). Effective Household Waste Management: A key to Sustainable Environmental Management in Anyakoha, E.U. (ed) Research issues in Home Economics, Nsukka: HERAN.

[11] Ezeoguine J. A., Journal of Home Economics Research 6(1) (2005) 156-160.

[12] Federal Government of Nigeria (FGN, 1998). Blue Print on Municipal Solid Waste Management in Nigeria. Abuja: Government Press.

[13] Federal Republic of Nigeria (FRN, 2005). National Environmental Sanitation Policy, Abuja: Federal Ministry of Environment.

[14] Folarin B. K. (2005). Problem of Waste Management in Warri Urban. Unpublished B.Sc. Thesis, Department of Geography, University of Nigeria Nsukka.

[15] Jimoh H. I. (2003). Techniques in Environmental Studies. IIorin: Aathedex Publishers.

[16] Katsina State Ministry of Works, Transport and Housing (2009). Katsina Urban and Rural Housing Development. Katsina: Katsina government press.

[17] Lapin O. (1997). 'Niger Delta Community Development Review. Final report prepared for the Shell petroleum company Ltd. In Ogbene A.E., Unpublished Ph.D thesis 2003 University of Nigeria, Nsukka.

[18] Nigerian Environmental Study Team (NEST, 1995). Environmental Awareness Training Mannual (EATM) Lagos: Fredrick Ebert Foundation (FEF).

[19] Onibokun A. G., Kumuyi A. J. (2006). Governance and Waste Management in Africa. International Development Research Centre. htt://archirefrcal-book/indes. htm. retrieved on $26 / 03 / 14$ 
[20] Ogbene A. E. (2003). Water Pollution Management Techniques of Home Makers in oil producing communities of Delta State. Unpublished PhD Thesis, University of Nigeria Nsukka.

[21] Onwuendo G. O. (2007). Development of an Intervention Programme for Improving on the hygiene Practices of Fast Food Industries in Anambra State. Unpublished Ph.D. Thesis, University of Nigeria Nsukka.

[22] Owens L. K. (2002). Introduction to Survey Research Design. Survey Research Laboratory (SRL) fall 2002 Seminar Series, Retrieved, March 16, 2014 from: http://www/srl/uie/edu.

[23] Saka G. O. (1995). Thy Waste be dumped, Strategies and household Management. Lagos. Goe the Institute.

[24] Ukwe U. C., Journal of Home Economics research 5(4) (2004) 97-100.

[25] Ukwe U. C., Journal of Home Economics Research 9 (2008) 43-52.

[26] United Nation (2003). Nutrition and the Environment Geneva (21), 3. 